\title{
STUDY OF PROPERTIES OF SOME POLYETHYLENE-CLAY NANOCOMPOSITES: INFLUENCE OF PREPARATION METHOD ON THE DEGREE OF CLAY INTERCALATION/EXFOLIATION
}

\author{
Fulga Tanasa*, Madalina Zanoaga \\ “Petru Poni” Institute of Macromolecular Chemistry, 41A, Grigore Ghica Voda Alley, Iasi 700487, Romania \\ *e-mail: ftanasa@icmpp.ro; phone (+40 232) 21 74 54; fax (+40 232) 211299 \\ Paper dedicated to the $65^{\text {th }}$ anniversary of the \\ “Petru Poni” Institute of Macromolecular Chemistry of Romanian Academy, Iasi, Romania
}

\begin{abstract}
New nanocomposites based on high density polyethylene (HDPE) and organically modified nanoclay (Cloisite 20A) were obtained by two different methods, namely melt compounding and solution blending, and their properties were comparatively studied by XRD, DSC, POM and SEM in order to establish the dependence of the clay degree of exfoliation/intercalation on the preparation procedure. Nanocomposites prepared in molten state under shear stress were found to posses the most extensive dispersion of nanometric clay particles and high levels of exfoliation.
\end{abstract}

Keywords: polymer-clay nanocomposites, preparation, properties, exfoliation, intercalation.

\section{Introduction}

Thermoplastic composites play an important role in our society, as their properties respond to a wide range of specific demands. They have, therefore, attracted considerable interest from both industry and academic media.

When clays and polymers are compatible, the properties conferred by the filler to the polymer matrix are comparable or exceed those of traditional materials. High levels of exfoliated layered silicate may be difficultly reached when highly hydrophobic materials, such as polyethylene (PE) and polypropylene (PP), are used. Maleic anhydride (MA) grafting proved to be the most efficient method to grant compatibility to PE and PP towards organoclays. Modern approaches use not only such compatibilizing agents (PP-g-MA and PE-g-MA), but also organically modified clays [1].

The high aspect ratio of the nanoclays provides a great interfacial area, thus enhancing reinforcing properties. Silicates, such as montmorillonite, hectorite, and saponite, have a layered structure that, upon exfoliation, leads to composites with very high stiffness and strength [2].

The most known methods for preparing polymer-clay nanocomposites are melt intercalation, in situ polymerization, and solution dispersion. The melt intercalation method is the most convenient at industrial scale due to the continuous nature of the process and economic factors. It was found that the orientation of clay in compatibilized polymer matrices (polymers grafted with maleic anhydride) increased with increasing shear rate. The hydrogen bridges between polymeric maleic anhydride units and oxygen-containing groups in the silicates may significantly contribute to the clay intercalation. But for an effective clay exfoliation, the shear stress addition was required.

The solution blending is a procedure of lesser importance compared to melt compounding, as it requires toxic/ aggressive solvents. Even so, significant levels of intercalation or exfoliation were achieved for linear low density polyethylene (LDPE) or polypropylene (PP) nanocomposites prepared from solution without compatibilizers $[3,4]$ and only microcomposites are known to be produced from the same components by melt-compounding $[5,6]$. Other studies reported that only un-intercalated microcomposites were obtained by this procedure, although a wide range of solvents was employed, and regardless the method applied for solvent removal (evaporation or precipitation in different nonsolvents) [7]. It was also reported [8,9] that nanocomposites prepared in molten state were the only ones displaying high degrees of exfoliation.

From a scientific point of view, a comparative study of the structure and morphology of polymer-clay composites obtained through different procedures is very useful when it comes to explain composites properties and behavior; it is also of great importance to understand the mechanisms and influence of the different parameters, such as the shear stress in melt compounding, the temperature, the polymer-organoclay compatibility, etc., on the intercalation/exfoliation processes.

New nanocomposites based on high density polyethylene (HDPE) and organically modified nanoclay (Cloisite 20A) were obtained by two different methods, namely melt compounding and solution blending, and their properties were comparatively studied in order to establish the dependence of the clay degree of exfoliation/intercalation on the preparation procedure. 


\section{Results and discussion}

The structure of phyllosilicates (nanoclays) (Figure 1) was extensively studied in correlation with their applications in polymer nanocomposites in order to reveal their effects on polymeric materials $[1,10,11]$.

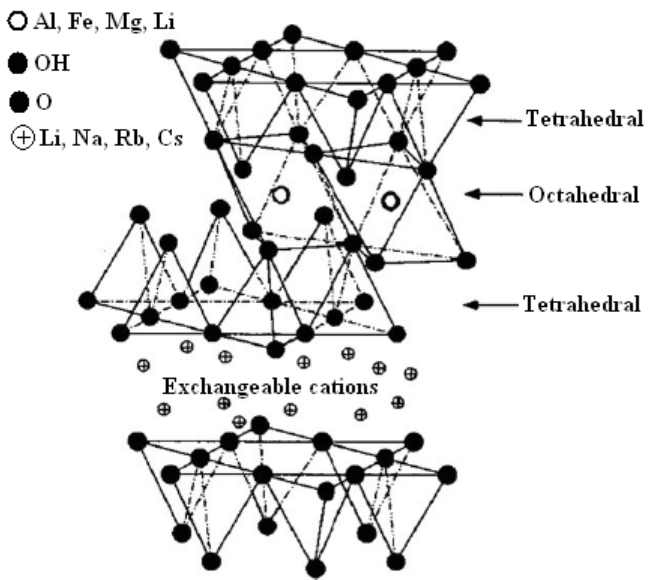

Figure 1. Structure of phyllosilicates (nanoclays).

Surface modification of clay has commonly been used to achieve a better compatibility of the clay and polymer. Ion exchange of $\mathrm{Na}^{+}$or $\mathrm{Ca}^{2+}$ cations present in the clay galleries by alkylammonium ions from organic modifiers is frequently used [10].

The thermal gravimetric analysis (TGA) of the unmodified montmorillonite displayed three mass loss stages: below $100^{\circ} \mathrm{C}$, at $135^{\circ} \mathrm{C}$ and at $450^{\circ} \mathrm{C}$ [11]. They were attributed to water desorption from clay, dehydration of the hydrated cations inside galleries and to the dehydroxylation of the montmorillonite, respectively. The presence of organic cations increases the number of decomposition steps, as follows: the first step is up to $66.9^{\circ} \mathrm{C}$ and is attributed to the desorption of water; the second occurs from $135.5^{\circ} \mathrm{C}$ to $310^{\circ} \mathrm{C}$ and is assigned to the loss of hydration water from $\mathrm{Na}^{+}$cations; the third one corresponds to the removal of the surfactant at approx. $440^{\circ} \mathrm{C}$; the last mass loss stage is associated to the loss of structural hydroxyl groups from clay and occurs around $580^{\circ} \mathrm{C}$. This is an indication of the thermal stability of modified clays [11].

DSC data for the neat polymers are presented in Table 1. HDPE-g-MA has lower melting temperature, melting heat and degree of crystallinity than HDPE, due to the presence of maleic anhydride groups that disrupt the order of the crystalline structure of polyethylene macromolecular chains.

Table 1

DSC data for neat polymers.

\begin{tabular}{cccc}
\hline Polymer & Melting point $\left({ }^{\circ} \mathrm{C}\right)$ & Melting heat $(\mathrm{J} / \mathrm{g})$ & Crystallinity $(\%)$ \\
\hline HDPE & 135.9 & 196.1 & 64.7 \\
HDPE-g-MA & 133.7 & 173.3 & 57.6 \\
\hline
\end{tabular}

The crystallization of nanocomposite samples prepared by solution dispersion or by melt blending has been studied according to a literature procedure [9], by isothermal DSC analysis in the range of crystallization temperatures of $120-124^{\circ} \mathrm{C}$ (Table 2).

Table 2

\section{Crystallization times for composite samples prepared by melt blending and from solution.}

Half crystallization time $\left(\mathrm{t}_{0.5}, \mathrm{~s}\right)$

\begin{tabular}{ccccc}
\hline \multirow{2}{*}{$\begin{array}{c}\text { Crystallization } \\
\text { temperature }\end{array}$} & \multicolumn{3}{c}{ Composite samples } \\
\cline { 2 - 5 }$\left({ }^{\circ} \mathrm{C}\right)$ & $\begin{array}{c}\text { HDPE 5 } \\
\text { melt }\end{array}$ & $\begin{array}{c}\text { HDPE-g-MA 10 } \\
\text { melt }\end{array}$ & $\begin{array}{c}\text { HDPE-g-MA 10 } \\
\text { sol }\end{array}$ & $\begin{array}{c}\text { HDPE-g-MA 15 } \\
\text { sol }\end{array}$ \\
\hline 124 & 255 & 308 & 202 & 170 \\
123 & 197 & 179 & 117 & 119 \\
122 & 165 & 141 & 93 & 73 \\
121 & 109 & 101 & 65 & 52 \\
120 & 91 & 80 & 45 & 49 \\
\hline
\end{tabular}


It is known that clay remains in solid state over the whole selected range of temperature during the DSC measurements. Thus, the recorded isothermal DSC traces consist of single exothermic peaks. As presented in Table 2, the addition of Cloisite 20A into HDPE and HDPE-g-MA matrices (melt blending) slightly modified the half-crystallization times of the corresponding polymers. For solution mixing samples, the presence of clay particles decreased the half crystallization times of the polymer matrix. These results are in good concordance with reported data [9].

The XRD patterns of the Cloisite 20A and of some of the composites prepared by melt blending are shown in Figure 2, while those for composites obtained by solution mixing are presented in Figure 3.

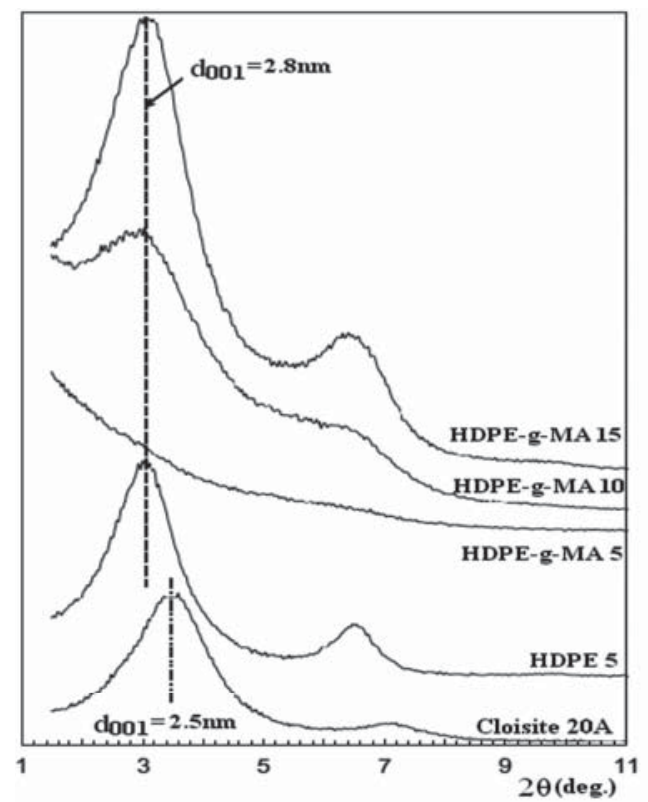

Figure 2. XRD patterns of Cloisite 20A and of some composites obtained by melt blending.

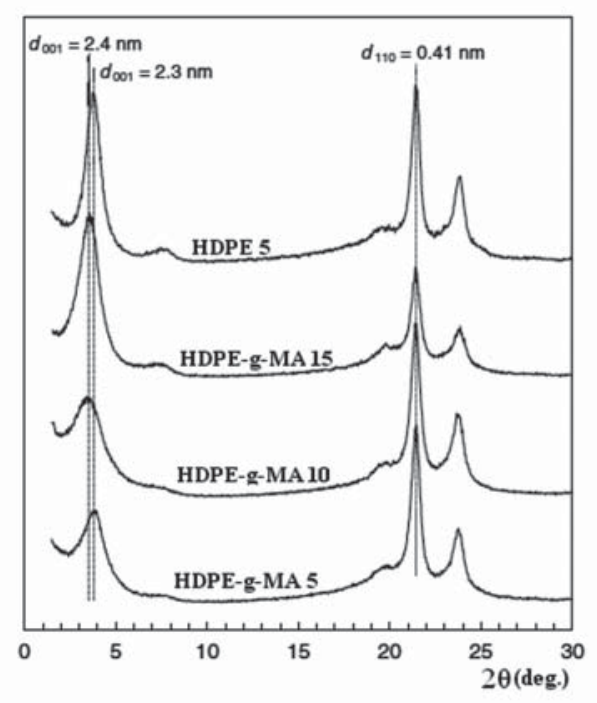

Figure 3. XRD patterns of some composites prepared by solution mixing.

The basal reflection at $2 \theta=3.5^{\circ}\left(\mathrm{d}_{001}=2.5 \mathrm{~nm}\right)$ characteristic to Cloisite $20 \mathrm{~A}$ (Figure 2 ) is slightly shifted to lower angles $\left(2 \theta=3.1^{\circ}, \mathrm{d}_{001}=2.8 \mathrm{~nm}\right)$ in the XRD spectrum of HDPE-3. Most authors agree that different PE grades yield in conventional microcomposites when melt blended with commercial organoclays $[5,8,12,13]$; thus, shifts of the basal reflection toward lower or wider angles have often been observed and were attributed to limited intercalation, interlayer reorganization, or to thermal decomposition of the surfactant inside the galleries [14]. In our case, the slight gallery expansion observed for HDPE 5 and HDPE-g-MA composites obtain by melt blending might be caused by the limited penetration of polyolefin macromolecules inside the clay galleries, observation consistent with literature data [14].

The behavior of the HDPE and HDMA composites prepared from solution is illustrated by the XRD patterns in Figure 3. It is known that the unbounded surfactant of an organoclay, added in excess with respect to the CEC of the clay during the cation exchange, can be removed by solvent extraction (e.g., with alcohols) [15,16]. It was also shown that an ethanol extraction of Cloisite 20A yielded in a product characterized by lower organic content (from 38.5 to 35.9 $\mathrm{wt} \%$ ) and interlayer distance (from 2.53 to $2.42 \mathrm{~nm}$ ) [7].

In our experiments, composites were prepared from solution by room-temperature solvent removal and the corresponding XRD patterns showed they contain a more or less intense basal reflection approximately at the same angular position as clay. Comparing Figures 2 and 3, it seems that HDPE-g-MA 15 composites are highly exfoliated when prepared in molten state, but contain ordered platelets stacks when prepared from solution.

Literature data showed the clay sheets, which are predominantly delaminated in the xylene dispersion $[15,16]$, tend to aggregate back into stacks during solvent evaporation. This is a well documented phenomenon, known in literature as the secondary aggregation which occurs due to the processing conditions [17]. Such phenomenon takes place along with the expulsion of the polymer chains, so that unintercalated silicate stacks are formed. A comparison of Figures 2 and 3 shows that the interlayer spacing of the HDPE 3 and HDPE-g-MA 15 composites obtained from solution is smaller than that of the same composites prepared in molten state, which is evidence in favor of intercalation for the latter.

Primary examination of composites morphology was performed by POM and the selected images of HDPE-gMA 10 samples are shown in Figure 4.

The image corresponding to the composite prepared by melt compounding appears almost completely dark, in agreement with the XRD suggestion that this is a highly exfoliated nanocomposite characterized by homogeneous 
dispersion of nanometric clay particles. The other image, corresponding to the composite prepared from solution, reveals the presence of birefringent particles quite uniformly distributed over the entire field. The SEM analysis results confirm these observations (Figure 5).
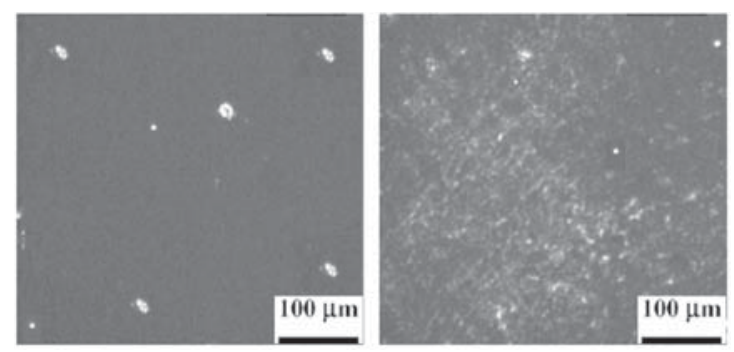

Figure 4. POM images of HDPE-g-MA 10 prepared by melt blending (left) and from solution (right).
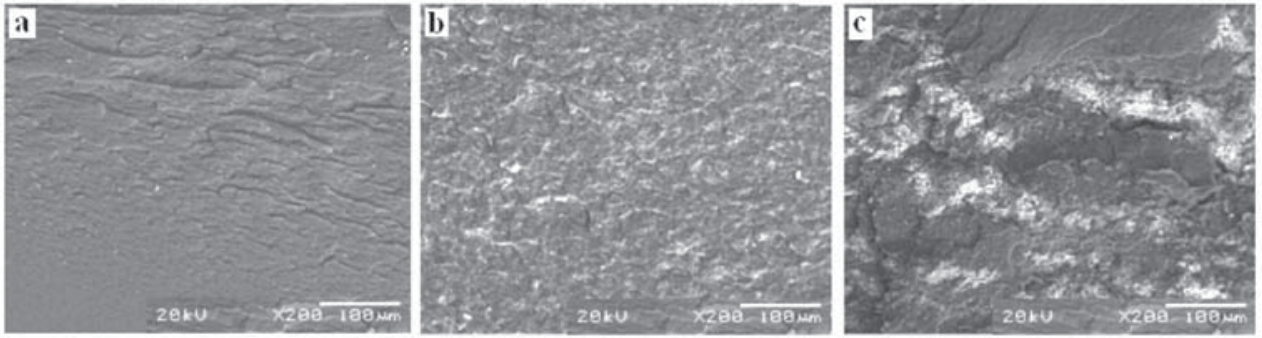

Figure 5. SEM micrographs of composite samples: a - HDPE 5 (melt blending), b - HDPE-g-MA 10 (melt blending), c - HDPE-g-MA 10 (from solution).

Micrographs of melt blended samples (Figure 5a and b) showed a fairly homogeneous distribution of filler inside the polymer matrix, despite the relatively high amount of clay in the corresponding formulations. This suggests a nanometric dispersion of exfoliated nanoparticles up to a certain degree, higher than that obtained through solution mixing, as suggested by micrograph $5 \mathrm{c}$ which shows a completely different texture, with rough areas (attributed to secondary agglomeration of clay platelets) distributed in an inhomogeneous manner in the polymer matrix.

This hypothesis was demonstrated in literature by SEM micrographs obtained for cryo-fractured samples after they were burned in order to remove the organic material (the polymer matrix), so that the inorganic phase was the only one remaining and it retained the initial shape from the corresponding composite [8]. In this way, it was possible to show the extensive local parallelism of the clay layers inside the melt compounded nanocomposites, which is completely absent in those obtained from solution.

A deeper insight into the morphology of these composites we presented in this study, by the means of transmission electron microscopy (TEM), is required in order to fully demonstrate the local parallelism between individual silicate platelets and tactoids, or thin stacks present in the matrix. These investigations are currently underway and will be published in a future article.

\section{Conclusion}

Nanocomposites based on HDPE and HDPE-g-MA, as matrix, and Cloisite 20A, as filler, were obtained by two different methods, namely melt compounding and solution mixing. Their properties were comparatively studied (DSC, XRD, POM and SEM) in order to establish the correlation between the preparation method and the degree of clay intercalation/exfoliation.

Solution mixing failed to produce intercalated composites, as long as solvent removal is made at room temperature. The organoclay is predominantly exfoliated when dispersed in a good solvent relative to the polymer, such is hot xylene, but it tends to aggregate during processing (when solvent is removed by evaporation), leading to the homogeneous dispersion of small amounts of unintercalated tactoids in the polymer matrix.

Still, microscopic analysis demonstrated that the preparation approach has a marked influence on the composites morphology. Thus, the presence of poorly dispersed, micron-sized, yet intercalated clay particles was revealed in composites prepared from solution, whereas the nanocomposites prepared in the melt under shear stress were found to posses the most extensive dispersion of nanometric clay particles and high levels of exfoliation. 
The results were attributed to different patterns of clay dispersion and degrees of intercalation/exfoliation achieved during different preparation procedures. They are relevant in terms of tailoring nanocomposites properties as to meet particular application demands.

\section{Experimental Materials}

For this study, the following materials were used:

- HDPE (MFI $2 \mathrm{~g} / 10 \mathrm{~min}$ and density $0.96 \mathrm{~g} / \mathrm{cm}^{3}$ ) was donated by LyondellBasell and HDPE-g-MA (Fusabond ${ }^{\circledR}$ E100) (MFI $2 \mathrm{~g} / 10 \mathrm{~min}$, density $0.96 \mathrm{~g} / \mathrm{cm}^{3}$, melting point $134^{\circ} \mathrm{C}$ and MA content $0.9 \%$ ) was provided by DuPont;

- the organoclay was Cloisite ${ }^{\circledR} 20 \mathrm{~A}$ which is dimethyl bis(hydrogenated tallow) quaternary ammonium chloride montmorillonite (hydrogenated tallow is a blend of saturated alkyl chains and contains $\sim 65 \% \mathrm{C} 18, \sim 30 \% \mathrm{C} 16$ and $\sim 5 \%$ C14), supplied by Southern Clay Products, Inc., having the following characteristics: organic load 95 mequiv/100 g clay; organic content $39.6 \mathrm{wt} \%$; density $2.83 \mathrm{~g} / \mathrm{cm}^{3}, \mathrm{~d}_{001}=24.2 \AA$ by XRS; particle size distribution: $<15 \mu \mathrm{m}(90 \%)$; moisture $<2 \%$.

Six composite formulations were prepared by two different methods, using the same amounts of organoclay: 5 , 10 and $15 \mathrm{wt} \%$, respectively. Thus, they were identified as HDPE 5, HDPE 10, HDPE 15, and HDPE-g-MA 5, HDPEg-MA 10, HDPE-g-MA 15, respectively.

\section{Composites preparation}

Solution mixing

About $5 \mathrm{~g}$ of polymer and $200 \mathrm{~mL}$ of xylene were placed in a flask equipped with stirrer and reflux condenser, which was immersed in an oil bath and held at $120^{\circ} \mathrm{C}$ under stirring until complete polymer dissolution. The appropriate volume of a dispersion of clay in the same solvent ( $2 \mathrm{wt} \%$ ), prepared by gentle heating at $60^{\circ} \mathrm{C}$ for $2 \mathrm{~h}$ under stirring, was then added to the polymer solution, stirring continued. The solution was placed in an aluminium pan and evaporated at room temperature, first at atmospheric pressure and then under vacuum.

Melt blending

The polymer pellets and the clay were dried in a vacuum oven at $60^{\circ} \mathrm{C}$ over the night and then fed to a HAAKE RHEOCORD 9000 mixer (equipped with two internal roller mixers and a capacity of mixing chamber of $50 \mathrm{~cm}^{3}$ ). As the mixing head is volume sensitive, the feeding amount is calculated by considering the volume of the cavity, density of the material and $85 \%$ of the capacity utilization. The molten composites were removed from the mixer and cooled naturally in air, at room temperature.

\section{Characterization techniques}

Differential scanning calorimetric (DSC) thermograms were recorded using a Pyris Diamond DSC (Perkin Elmer, USA) at a heating rate of $10^{\circ} \mathrm{C} / \mathrm{min}$ under dry $\mathrm{N}_{2}$ atmosphere. The specimens were heated up to $190^{\circ} \mathrm{C}$ and kept at this temperature for $5 \mathrm{~min}$ in order to destroy the polyethylene crystal nuclei. The DSC cooling traces were recorded at a rate of $10^{\circ} \mathrm{C} / \mathrm{min}$. The degree of crystallinity was calculated from the crystallization enthalpy, normalized to the amount of polymer.

XRD patterns were recorded on a Bruker AD8 Advance diffractometer. The spacing basal of the samples was observed at room temperature $(40 \mathrm{kV}, 30 \mathrm{~mA})$ using $\mathrm{CuK} \alpha$ radiation $(\lambda=0.154 \mathrm{~nm})$ at the rate of $2 \% / \mathrm{min}$. All diffractograms were reported as observed.

Polarized optical microscopy (POM) observations were made using an Olympus BH-2 polarized light microscope equipped with a THMS600/HSF9I heating stage. The optical observations were performed by using clean untreated glass slides.

The morphology of the fracture surface of the nanocomposites was investigated by using a scanning electron microscope (SEM) VEGA II SBH instrument manufactured by TESCAN (Brno, Czech Republic). Samples were cryogenically fractured by immersion in liquid nitrogen for 30-50 minutes. Shortly after fracturing, the rupture surfaces were coated with a thin gold layer (of about $50 \mathrm{~nm}$ ) prior to examination under the electron beam. An operating voltage of $30 \mathrm{kV}$ was used.

\section{Acknowledgements}

Authors gratefully acknowledge the scientific contribution of Dr. Luminita Marin.

\section{References}

1. Bhattacharya, S. N.; Kamal, M.; Gupta, R. Polymeric Nanocomposites: Theory and Practice. Carl Hanser Verlag: Munich, 2008, 383 p.

2. Hetzera, M.; De Keea, D. Wood/polymer/nanoclay composites, environmentally friendly sustainable technology: A review. Chemical Engineering Research and Design, 2008, 86, pp. 1083-1093. 
3. Qiu, L.; Chen, W.; Qu, B. Morphology and thermal stabilization mechanism of LLDPE/MMT and LLDPE/LDH nanocomposites. Polymer, 2006, 47, pp. 922-930.

4. Chiu, F. C.; Chu, P. H. Characterization of solution-mixed polypropylene/clay nanocomposites without compatibilizers. Journal of Polymer Research, 2006, 13, pp. 73-78.

5. Chiu, F. C.; Lai, S. M.; Chen, J. W.; Chu, P.H. Combined effects of clay modifications and compatibilizers on the formation and physical properties of melt-mixed polypropylene/clay nanocomposites. Journal of Polymer Science Part B: Polymer Physics, 2004, 42, pp. 4139-4150.

6. Hotta, S.; Paul, D. R. Nanocomposites formed from linear low density polyethylene and organoclays. Polymer, 2004, 45, pp. 7639-7654.

7. Filippi, S.; Mameli, E.; Marazzato, C.; Magagnini, P. Comparison of solution-blending and melt-intercalation for the preparation of poly(ethylene-co-acrylic acid)/organoclay nanocomposites. European Polymer Journal, 2007, 43, pp. 1645-1659.

8. Filippi, S.; Marazzato, C.; Magagnini, P.; Famulari, A.; Arosio, P.; Meille, S. V. Structure and morphology of HDPE-g-MA/organoclay nanocomposites: Effects of the preparation procedures. European Polymer Journal, 2008, 44, pp. 987-1002.

9. Minkova, L.; Filippi, S. Characterization of HDPE-g-MA/clay nanocomposites prepared by different preparation procedures: Effect of the filler dimension on crystallization, microhardness and flammability. Polymer Testing, 2011, 30, pp. 1-7.

10. Hetzer, M.; De Kee, D. Wood/polymer/nanoclay composites, environmentally friendly sustainable technology: A review. Chemical Engineering Research and Design, 2008, 86, pp. 1083-1093.

11. Singla, P.; Mehta, R.; Upadhyay, S. N. Clay modification by the use of organic cations. Green and Sustainable Chemistry, 2012, 2, pp. 21-25.

12. Spencer, M. W.; Cui, L.; Yoo, Y.; Paul, D. R. Morphology and properties of nanocomposites based on HDPE/ HDPE-g-MA blends. Polymer, 2010, 51, pp. 1056-1070.

13. Shah, R. K.; Paul, D. R. Organoclay degradation in melt processed polyethylene nanocomposites. Polymer, 2006, 47, pp. 4075-4084.

14. Paul, D. R.; Zeng, Q. H.; Yu A. B.; Lu, G. Q. The interlayer swelling and molecular packing in organoclays. Journal of Colloid and Interface Science, 2005, 292, pp. 462-468.

15. Ho, D. L.; Briber, R. M.; Glinka, C. J. Characterization of organically modified clays using scattering and microscopic techniques. Chemistry of Materials, 2001, 13, pp. 1923-1931.

16. Ho, D. L.; Glinka C. J. Effects of solvents solubility parameters on organoclay dispersions. Chemistry of Materials, 2003, 15, pp. 1309-1312.

17. Dorigato, A.; Dzenis, Y.; Pegoretti, A. Filler aggregation as a reinforcement mechanism in polymer nanocomposites. Mechanics of Materials, 2013, 61, pp. 79-90. 